\title{
Prospects for tidal stream energy in the UK and South America: A review of challenges and opportunities
}

\author{
C. R. Vogel ${ }^{1 *}$, D. T. Taira², B. S. Carmo ${ }^{2}$, G. R. S. Assi ${ }^{3}$, R H. J. Willden ${ }^{1}$, J. R. Meneghini² \\ ${ }^{1}$ Department of Engineering Science, University of Oxford, Oxford, United Kingdom \\ ${ }^{2}$ Department of Mechanical Engineering, EPUSP, University of São Paulo, São Paulo, Brazil \\ ${ }^{3}$ Department of Naval Architecture \& Ocean Engineering, EPUSP, University of São Paulo, São Paulo, \\ Brazil
}

\section{$\underline{\text { Abstract }}$}

Concerns about energy production and climate change are driving transitions towards renewable electricity sources around the world. Tidal stream energy has been identified as an energy source with potential as both a renewable and predictable resource, particularly in regions with established offshore industries. Tidal stream technology is at a relatively early stage of development in comparison to wind and solar, and a number of challenges including environmental impact, cost reduction and technology must be addressed in order to achieve commercial competitiveness. This article briefly compares and contrasts the potential for tidal stream energy in two regions at different levels of maturity, the United Kingdom and South America, and identifies some of the common challenges and opportunities for knowledge transfer between these regions. An overview of the current state of the tidal industry and research landscape is also presented. There is the potential for significant progress in the development of the tidal energy sector if an integrated approach to research and development is taken between regions.

Keywords: Tidal stream energy; United Kingdom; Brazil; Chile

\section{Introduction}

The energy sector worldwide is undergoing a substantial transformation driven by concerns about sustainability, energy security, and changing demand patterns. The importance of affordable, reliable and sustainable energy as a key aspect of development and prosperity has been enshrined as one of the 17 Sustainable Development Goals adopted by the United Nations (UN) [1]. There is growing international consensus about the need for action to reduce the climate impact of the energy sector, as outlined in the Intergovernmental Panel on Climate Change (IPCC) report on the impacts and risks of an increase of global temperature of $1.5^{\circ} \mathrm{C}$ above pre-industrial levels [2]. Reductions in anthropogenic $\mathrm{CO}_{2}$ emissions of around $45 \%$ from 2010 levels are required by 2030, reaching net-zero by 2050 , in order to limit temperature rises to $1.5^{\circ} \mathrm{C}$. Internationally, governments are responding to this challenge with national proposals of how countries might meet the targets required for net-zero emissions by 2050 [3], [4].

Strategies to meet these targets, for example in the UK, typically focus on the decarbonisation of the electricity sector in advance its expansion to decarbonise the traditionally carbon-intensive heating and transport sectors [5]. This requires not only the displacement of fossil fuels from the electricity sector, but also the expansion of clean generation technologies. Annual growth in total energy demand is relatively low in developed economies such as the UK, with the main energy transition being that to renewable energy sources. The UK has traditionally had a carbon-intensive electricity sector, but has seen a substantial growth in renewable energy generation over recent 
decades from $1.9 \%$ of total electricity production in 1990 to $29.3 \%$ in 2017 , largely driven by the expansion of wind and solar energy [6]. Other countries have had a long track record of renewable energy generation, such as Brazil, which is dominated by a large hydroelectricity sector supplying over $65 \%$ of electricity in 2017 , whereas wind and solar represented less than $7 \%$ of electricity generation [7]. Brazil's robust economic growth resulted in a doubling of total energy demand between 1990 and 2017, and continued expansion of hydropower is increasingly challenging given the environmental sensitivities and remoteness of the remaining resource [8], [9]. Consequently, alternative renewable energy sources will be required to sustain the continued clean expansion of Brazilian energy production.

The ocean economy was estimated to be worth $\$ 1.5$ trillion in 2010, with over one-third being in the offshore energy sector, primarily oil and gas [8]. Traditionally, both the UK and Brazil have had strong offshore energy sectors through the exploitation of offshore oil and gas in the North Sea (UK) and the Santos Basin (Brazil). Brazil is currently a world-lead in deepwater oil and gas production, and is forecast to maintain this position for several decades to come [9]. With the decline in oil and gas production in the offshore energy sector in the UK has increasingly been focussed on the development of offshore renewable energy, especially offshore wind energy. The UK has seen rapid developments in both offshore wind capacity, forecast to reach $30 \mathrm{GW}$ by 2030, and substantial reductions in Levelised Cost of Energy (LCOE) [10]. Globally, more than $80 \%$ of offshore wind capacity is located in Europe, although the sector is developing rapidly in Asia (China, Japan) and the United States [11]. The developments in offshore energy infrastructure that have accompanied this growth, including foundations, cabling, and transmission technology are expected to have ancillary benefits in supporting the development of less mature offshore energy technologies [11]. Indeed, the IEA have identified Brazil, Uruguay, and Argentina has locations with strong potential for offshore synergies due to the established offshore industries and centres of large energy demand near the coast [11].

It is widely accepted that a diverse range of renewable generation technologies must be developed in order to deliver a reliable and consistent electricity supply, given that renewable technologies such as wind and photovoltaics are intermittent and prone to rapid fluctuations in capacity [12]. A spatially and technologically diverse portfolio of renewable generation sources has the potential to mitigate intermittency in overall energy production as intermittent sources tend to vary independently of each other [13]. Marine renewable energy therefore may make an important contribution to future energy networks. Tidal energy is a particularly promising resource, as although intermittent, the tides are predictable which has significant benefits for electricity networks [14].

Estimates of the global tidal energy resource are relatively uncertain at present, with estimates reported in the literature ranging between 500-1200 TWh/y [15] and $26000 \mathrm{TWh} / \mathrm{y}$ [16]. Only a fraction of the available resource is likely to be techno-economically feasible to harness. The resource is not evenly distributed around the world; for example the UK's estimated is around $50 \mathrm{TWh} / \mathrm{Y}$ [14]. The marine energy sector is at a nascent stage of development in contrast to offshore wind, and consequently future installation forecasts are for relatively modest deployments. The Sustainable Development Scenario developed by the IEA forecasts installed marine energy capacity (wave and tidal) to exceed $30 \mathrm{GW}$ in 2040, with 85 TWh production, roughly one tenth of that of offshore wind [11].

\section{Tidal stream resource}


Tides arise from the gravitational interaction between the Earth and astronomical bodies, principally the Moon and Sun. The theory of the dynamics of tide raising forces was proposed by Laplace [17], utilising a series of satellites to represent the different amplitudes and phases of the tide raising force constituents. Harmonic analysis of the tides reveals over one hundred tidal constituents, although just seven constituents are needed to describe around $80 \%$ of tidal amplitude and phase variation [18]. The tides are thus very predictable and therefore an attractive energy resource. Furthermore, the direction of associated flows of water are often more predictable than wind, as the sea surface and surrounding environment act to constrain the currents.

The tidal energy flux in the deep oceans is small and generally too low for economic energy generation. It is at the coasts, where the energy flux is concentrated, that tidal energy extraction may be economically feasible. The concentration of the tidal energy flux near the coasts is a consequence of the interactions and reflections of the various tidal constituents between the deep oceans and coastal shelves, and thus varies spatially around the world [19]. Coastal bathymetry, in particular with narrowing channels and estuaries also plays an important role in concentrating tidal energy as shown in Figure 1. In some regions the width of the continental shelf is close to one-quarter of a tidal constituent wavelength, leading to large amplifications of the tidal amplitude and thus large tidal flow speeds. The Bay of Fundy in Canada and the Bristol Channel in the UK are examples of two such locations [19]. Additionally, strong tidal currents can also be established in channels and straits where there is a substantial phase difference in tidal elevation at either end, such as Cook Strait, NZ [20].

\section{$2.1 U K$}

The UK's location between the North Atlantic Ocean and North Sea at close to one-quarter of the $\mathrm{M} 2$ semi-diurnal tidal constituent from the edge of the European continental shelf results in significant concentration of tidal energy at points along the UK coastline, as indicated in Figure 2 . The highest flow speeds are observed in regions of shallow water around flow constrictions such as headlands, straits, and channels. Peak tidal flow speeds of over $2 \mathrm{~ms}^{-1}$ are observed in the Bristol Channel, Anglesey Skerries and English Channel, and around $5 \mathrm{~ms}^{-1}$ at locations in the Pentland Firth north of Scotland [21]. Around $80 \%$ of the UK's tidal stream technical resource can be found at ten sites, dominated by the Pentland Firth which represents around one third of the total resource [22].

Water depth in significant fractions of the UK near-offshore zone, in particular around the Irish Sea and Pentland Firth is between $20-70 \mathrm{~m}$. Understanding of seabed conditions for foundations has advanced significantly with the rapid expansion of offshore wind turbine deployment using monopile foundations, which may be transferrable to the tidal stream industry. At deeper sites, floating platforms may be a more attractive technology, as is being pursued by a number of companies. However, the highly energetic sites favourable for tidal energy development can also be co-located with important marine habitats [23]. For example, Strangford Lough has large breeding colonies of harbour porpoises and harbour seals, and Lieber et al. and Pine et al. showed that tidal devices have an acoustic impact on those species [24] [25]. Detailed and site specific studies will be required for each site of interest accounting for the technology being deployed and the species present.

The strong potential for tidal stream energy in the UK has attracted interest for a number of years. The UK is home to two tidal stream energy test centres with a further two undergoing consenting processes, covering a range of technology development stages. The European Marine Energy Centre (EMEC) was established in Orkney in 2003 and contains two scaled test sites and thirteen open-sea 
grid connected test berths. FaBTest in Falmouth Bay, Cornwall was established in 2011, and offers three berths for testing in the relatively benign environment of Falmouth Bay with tidal flow speeds of up to $0.8 \mathrm{~ms}^{-1}$. The Marine Energy Test Area (META) is currently being established in Pembrokeshire, and has flow speeds of up to $1.2 \mathrm{~ms}^{-1}$. The Morlais Tidal Demonstration Zone will encompass a substantial area of $35 \mathrm{~km}^{2}$ off West Anglesey. Peak flow speeds off Anglesey and Holy Island have been observed at up to $3.7 \mathrm{~ms}^{-1}$.

\subsection{South America}

South America has a very long coastline, dominated by Brazil on the east coast and Chile on the west coast. In Brazil, 27\% of the population (around 51 million inhabitants) occupy urbanized areas along $7,491 \mathrm{~km}$ of coastline. The tides around Brazil are semidiurnal, whereas they are mixedsemidiurnal further south, with peak tidal ranges of up to $8 \mathrm{~m}$ found around the Maranhense Gulf in São Marcos Bay [26]. The highest tidal current flow speeds in Chile are found towards the south, and are dominated by the $\mathrm{M}_{2}$ tidal constituent by an order of magnitude [27]. Relatively strong currents are found in the fjords in Southern Chile, particularly where narrow bathymetries and estuaries result in substantial tidal amplification [28], [29]. Peak flow speeds of up to $4 \mathrm{~ms}^{-1}$ and turbulence intensities of $10-20 \%$ have been observed in the Chacao Channel, located in the northernmost part of Chilean Patagonia [27], and around $4.5 \mathrm{~ms}^{-1}$ in the Magellan Strait [30]. It is believed that there is little prospect for tidal stream energy in northern and central Chile. There may also be regions with favourable bathymetry including headlands in the mid Rio de la Plata Estuary in Uruguay where tidal stream energy may be feasible to exploit [31].

Assessment of the tidal energy resource in South America has been limited to a small number of potential sites to date as shown in Figure 2, and further work is required to better understand the potential resource that is available. The high flow speeds of the Chacao Channel has attracted a number of studies, with the energy density in the Channel comparing favourably to other energetic sites around the world. Guerra et al. performed field measurements using Acoustic Doppler Current Profilers (ADCPs) and developed a numerical model using Finite-Volume Community Ocean Model (FVCOM) of the Chacao Channel and showed that the average kinetic power density is greater than 5 $\mathrm{kWm}^{-2}$ more than $20 \%$ of the time [27]. The Chacao Channel is relatively isolated, and Villalón et al. showed that any tidal stream plant would be limited to $45.6 \mathrm{MW}$ unless the transmission system could be upgraded [32]. However, strong lateral shear in tidal flow speeds has been observed in the Channel, which may affect planning of tidal stream energy developments [28]. The Chacao Channel is also an important marine ecological area, including as a feeding ground and nursery for blue whales [33].

Tidal stream energy potential has been evaluated at a few locations in Brazil. González-Gorbeña et al. used a two-dimensional hydrodynamic model to identify São Marcos Bay, located in the state of Maranhão as a region with annual power density in the range from 9.2 to $11.2 \mathrm{MWhm}^{-2}$ [26]. MartaAlmeida et al. investigated the energy available in the estuary of Baía de Todos os Santos, located in Brazil's northeast [34]. The Baía de Todos os Santos is the second largest bay in Brazil, and is near Salvador, the third largest city in Brazil [34]. A numerical assessment estimated that the power density in this region reaches a daily average around $400 \mathrm{Wm}^{-2}$, peaking at around $2.5 \mathrm{kWm}^{-2}$ for the surface layer when allowing for a minimum operating flow speed of $1 \mathrm{~ms}^{-1}$.

South America also benefits from large estuaries such as the Amazon and Rio de la Plata [35] and significant ocean currents near its coastlines, including the Brazilian and Malvinas currents [36]. Whilst 
not strictly tidal currents, hydrokinetic turbines may still present a feasible technology for harnessing this energy. The Rio Grande do Sul littoral off the South-eastern coast of Brazil was found to have peak current speeds of over $1.5 \mathrm{~ms}^{-1}$, with flow speeds further enhanced in some coastal areas through headlands or straits between islands [36].

South America faces challenges in achieving efficient power extraction using tidal stream turbines, as there are relatively few sites that meet the requirements of peak tidal current speeds between 2 to $2.5 \mathrm{~ms}^{-1}$ at moderate depths of 20 to $50 \mathrm{~m}$ in regions where the seabed is favourable to offshore foundations [26]. However, as tidal stream technologies develop there may be the potential for further sites to become feasible for development.

\section{$3 \quad$ Harnessing tidal stream energy}

Tidal stream turbines are designed to extract energy from the bulk motion of water in tidal currents. Typically, peak flow speeds in excess of $2 \mathrm{~ms}^{-1}$ are required for economically viable energy extraction. One of the key differences between tidal stream turbines and more established tidal barrage technology is that a barrage is not used to establish a pressure head across the turbines, and instead energy is harnessed from the movement of tidal flows. One of the challenging aspects of tidal stream energy is that there is a complex and multi-scale interaction between the available tidal resource, flow past and through turbine farms, and the hydrodynamics of the turbines themselves.

\subsection{Regional scale}

As discussed in Section 2, regions in which tidal stream energy may be most economical to harness are those in which the tidal energy flux in the oceans is concentrated by the bathymetry of the continental shelf and geographical features such as islands, headlands, and straits or channels. Analytical models of the tidal stream energy available at such sides have been studied by a number of researchers [37]-[39], as idealised representations of real channels such as the Pentland Firth, UK or Cook Strait, NZ, in order to establish upper limits to the power available at those sites. Tidal flows may be driven by a head difference or phase difference across a region, or a combination of both. Given the large scale (tens of kilometres) of regional scale models, the turbines are represented as momentum sinks, which means care is required when relating turbine thrust to the hydrodynamic power available.

Site-specific investigations of tidal energy extraction necessitate a numerical modelling approach. The large horizontal extent, relative to the vertical dimension, of the regional models required for site investigations mean that depth-averaged shallow water modelling is usually the most appropriate modelling technique. Shallow water flow models are well-established and have been applied in many different applications, including coastal flows, flood modelling, and pollutant dispersal [40], [41]. Application to tidal stream energy problems is a more recent phenomenon and has required addition of energy extraction terms in the governing shallow water equations [42]. Applying shallow water codes to tidal energy extraction requires the availability of appropriate bathymetric data as well as the dominant tidal harmonics and seabed roughness at the site of interest [43], [44]. In some regions with high tidal ranges it is particularly important to model the wetting and drying of the inter-tidal zone in order to accurately capture the dynamics and effects of tidal energy extraction [45]. The dimensions of the numerical grids, with minimum cell edge lengths typically on the order of tens or hundreds of metres, necessitates the use of appropriate sub-grid scale turbine modelling to represent tidal farms [42], [46]. In particular, the lateral and streamwise smearing of turbine resistance needs to 
be carefully matched to ensure that the numerical model removes the correct amount of momentum from the flow.

One outcome of regional scale modelling, whether numerical or analytical, is that the resistance presented turbine farms to the tidal resource results in a reduction in the flow rate through the channel, which may have a significant impact on the tidal environment [37], [39]. Thus, it is important not only to consider turbine thrust but also the drag presented by support structures [47]. The impact of the tidal farm on the tidal resource is a function of both the total resistance presented by the turbine farm, as well as the underlying dynamics of the tidal site. The power that be extracted from a site is thus a balance between increasing numbers of turbines and the resulting reduction in energy flux [37]. Large straits with high levels of background friction are relatively insensitive to the resistance presented by the turbine farm, and therefore changes in tidal flows are relatively small [37]. On the other hand, small channels with low levels of friction are very sensitive to the effects of resistance presented by a tidal farm, and significant changes in the natural tidal flows are observed. Consequently, detailed understanding of turbine and farm performance is required in order to evaluate the energy that can be extracted from the tidal resource at each site.

\subsection{Turbine and farm scale}

Tidal stream turbines extract energy from an open channel flow without using a barrage to establish a drop in static pressure across the turbines (pressure head $h_{\mathrm{t} 2}$ to $h_{\mathrm{t} 3}$ in Figure 3). One of the key differences between wind and tidal flows is the close proximity of boundaries to tidal turbines, including the seabed, surface, and potentially neighbouring turbines. Approximating the tidal turbine as an actuator disk, Garrett and Cummins [48] demonstrated that operating turbines in a confined flow increases the maximum power coefficient $C_{P}$, turbine power normalised on the undisturbed kinetic flux through the rotor swept area, above the well-established Betz limit $C_{P}=16 / 27$ for wind turbines. Neglecting deformation of the free-surface, Garrett and Cummins showed that the maximum power coefficient for an idealised turbine in a confined flow was given by $C_{P \max }=$ $16 / 27(1-B)^{-2}$, where the blockage ratio $B$ is the ratio of turbine swept area to the cross-sectional area of the surrounding flow passage. This analysis was later extended to the case of an idealised turbine operating in an open channel flow, where deformation of the free surface results in a further increase in the power coefficient and acceleration of the downstream flow [49], [50].

The increase in maximum power coefficient for the idealised turbine in confined flows is due to the acceleration of flow in the bypass region around the turbine leading to a reduction in the downstream static pressure and the consequent increased pressure drop across the turbine plane. The turbine can thus achieve a higher thrust and therefore power for a given flow rate through the turbine. Maximising turbine power in a blocked environment requires that the turbine operates at a higher thrust than for an unblocked turbine. It should also be noted however that further mixing between the turbine wake and bypass flows occurs downstream, dissipating energy in the flow and thus limiting the overall efficiency of power extraction [51].

In practice, it is likely that tidal stream turbines will be deployed close together in fences or arrays due to constraints imposed by site licensing, environmental and bathymetric considerations, other maritime users, and to maximise sharing of infrastructure such as cabling. Resistance presented by the tidal farm will result in large-scale diversion of flow around the turbine array, leading to two-scale flow. Nishino and Willden [52] extended the single-turbine theory of Garrett and Cummins [48] to 
develop an analytical model of the farm and turbine scale flow past a tidal farm, neglecting deformation of the free surface. This was further extended by Vogel et al [53] to consider the effects of free surface deformation, resulting in slightly higher limits to power extraction.

Two scales of blockage can be defined for the multi-scale problem: local blockage $B_{L}$, the ratio of turbine swept area to the cross-sectional area of the surrounding flow passage for a single turbine; and global blockage $B_{G}$, the ratio of the frontal area of the turbine farm to the cross-sectional area of the channel. One of the key results of two-scale theory is that there is an optimal turbine spacing that maximises overall farm power. In the case of a turbine array in a very wide channel such that the global blockage tends to zero, farm power is maximised by closely spacing the turbines to achieve a local blockage of approximately $40 \%$, which results in a $34.5 \%$ increase in the maximum farm power coefficient above the Betz limit [52].

The theoretical limits to power extraction for both single turbines and turbine farms were developed using idealised turbine representations and require tidal turbines to operate at higher thrust coefficients (thrust normalised by undisturbed momentum flux) than wind turbines [48]. Practically achieving elevated levels of thrust in blocked environments may be achieved by running turbines designed for unblocked flows at higher rotational speeds, although this does not maximise power relative to the theoretical maximum. Furthermore, there may be concerns about cavitation inception by running devices at high speeds [54]. Alternatively, the rotor blade twist and solidity profiles can be redesigned to achieve the required levels of thrust at lower rotational speeds [55].

\subsection{Device analysis and design}

Similar to wind turbines, designs for tidal stream turbines may be largely categorised into two general categories: drag-driven devices, and lift-driven devices. Drag devices are relatively simple and rugged in design, but typically have very low efficiency and are therefore generally considered unattractive for large-scale tidal developments. Lift devices are typically much more efficient than drag devices, and are further sub-divided into three types: horizontal axis turbines; cross-flow turbines, and oscillating hydrofoils as shown in Figure 4. A number of lift-driven devices have been further designed using ducting around the turbine to align and accelerate the flow past the rotor [51], [56]. Whilst ducting can have a beneficial effect on turbine performance, the large surface area of the duct means that significant regions of flow separation can develop, particularly in yawed flows, and thus the environmental impact increases substantially. As detailed in Section 4, development has largely converged on the horizontal axis turbine without ducting, informed by decades of experience in the wind industry.

Idealised turbine representations using actuator disks allow limits to the efficiency of energy extraction to be established, but more realistic turbine representations are required in order to better reflect the performance of real turbines. As for wind turbines, a range of different analytical, numerical and experimental tools are available. These tools need to be modified to account for the effects of blockage on turbine performance, as well as differences in the flow environment including surface waves, velocity shear profile, and ambient turbulence levels. Different levels of model fidelity are used to incorporate these different factors.

Blade Element Momentum (BEM) theory is widely used in the wind industry to design turbines and evaluate performance [57]-[59]. The turbine is represented as an actuator disk in which the blade forces are azimuthally averaged over one revolution. The blade forces vary radially, although it is 
assumed that the fluid dynamics of each radial station is independent of all other radial stations. This allows two dimensional blade element theory to be combined with linear and rotational momentum theory in order to evaluate turbine performance [57], [58]. The model requires that the rotor blade geometry is specified, as are the lift and drag characteristics of the aerofoil(s) used along the rotor blades. BEM models therefore provide an efficient, albeit simplified representation of turbine performance, and an extensive range of corrections have been proposed to better account for challenging conditions including heavily loaded rotors and three dimensional flow effects such as tip losses [60]-[62].

BEM theory for wind turbines does not account for the effects of blockage on turbine performance, and therefore underestimates the loads on turbines. Vogel et al [63] extended BEM theory to turbines operating in blocked flows by modifying the streamwise momentum equations to account for the effects of blockage. Predictions of rotor thrust and power agree well with high-fidelity blade resolved computations, although the radial variation in blade loading near the rotor tips is not predicted well due to the lack of appropriate tip loss models for rotors in blocked flows.

An alternative approach is to embed actuator disks in computational domains and solve numerically the three-dimensional flow, including blockage effects. The actuator disk is typically represented as an internal porous boundary condition, and the two-dimensional blade element equations are used to determine the appropriate thrust and torque forces developed by the incident flow, which are then imposed on the flow [64]-[66]. Correction factors are required to account for tip losses and other three-dimensional flow phenomena. Whilst blade element actuator disk models can give good estimations of turbine thrust and power, and the velocity deficit in the wake can be predicted with reasonable accuracy in the wake greater than 3-4 diameters downstream of the turbine, experience in wind and tidal energy applications has shown that the disk does not capture some of the discrete structures, such as tip vortices, that are required to predict the variation in spanwise loading along the turbine blades [67], [68]. This limitation can be addressed by using actuator line methods, in which the turbine forces, calculated using blade element theory, are imposed on the flow using rotating lines [67], [68]. Whilst this approach captures some of the important flow features including the shed wake structure, near wake physics and three-dimensional blade flows are still not resolved.

BEM theory, actuator disk and actuator line models require good quality two-dimensional hydrofoil lift and drag characteristics. To date, hydrofoils used for tidal applications have tended to be derived from aerofoils used for wind turbines e.g. [69], [70], with a preference for thicker foil sections in order to meet the increased loads developed in water, which has a density close to 800 times that of air. A comprehensive discussion of evaluating foil characteristics given the ambient levels of turbulence and chord-based Reynolds number is given in Cao et al. [71].

High fidelity blade resolved simulations provide the greatest modelling accuracy as complex three-dimensional flow physics are directly resolved in the simulation. Blade resolved simulations are required in non-uniform flow conditions, such as due to shear profiles or in the presence of waves, as the unsteady flow physics is not captured by the assumptions of steady uniform flow in blade element theory [54], [67]. However, the spanwise twist and solidity profiles that are required can result in very large meshes, particularly when the blade boundary layer is resolved. Furthermore, the mesh interfaces between rotating and non-rotating sub-domains require sufficient resolution to ensure that flow structures are accurately communicated between different domains. However, it is possible to 
achieve very good agreement between blade resolved turbine simulations and numerical experiments, as recently shown by McNaughton et al for tests conducted at FloWave [72].

A combination of modelling methods are required to address challenges facing tidal stream energy. Increasingly, floating platforms are being proposed as design solutions which provide improved accessibility for installation and maintenance as compared to traditional seabed mounted foundations. However, the relative flows induced by platform motion introduce an unsteady component of turbine loading which needs to be understood in order to quantify the potentially significant unsteady blade loads that arise and the consequent on the fatigue lifetime of the turbine [73]-[75]. Furthermore, turbine blades will deform under high loading conditions, resulting in blade deformations that alter the hydrodynamic performance of the turbines. This is a highly coupled fluidsstructure problem also encountered in wind turbine applications [76]-[78], although the higher density of water may mean that the phenomenon is more significant across a greater portion of the turbine's operating window.

\subsection{Coupling across scales}

The fluid mechanics of tidal stream energy means that the physics of energy extraction at the smallest blade boundary layer scales gives rise to the overall hydrodynamic characteristics of tidal turbines, which in turn interact hydrodynamically with neighbouring turbines, aggregating to present resistance as a turbine farm to the tidal stream resource, which may have large scale impacts on tidal flows over tens of kilometres. Coupling of the different scales is important in order to evaluate the full impact and potential of tidal stream energy. For example, Nishino and Willden [52] combined turbine and farm scale flows to develop theories about the optimal turbine-turbine spacing for fences of turbines. This theory has been coupled with a channel dynamics model analytically [79] and numerically [80] to evaluate the impacts of energy extraction at turbine, farm, and channel scales, highlighting the interdependence of each scale on the dynamics of the other scales.

Multi-scale modelling of tidal fences shows that cross-fence variations in turbine thrust and power, and thus flow speed variations, develop across fences of finite length, particularly for turbines towards the ends of the array [81]-[85]. This is due to the presence of large bypass regions around the array causing an asymmetrical resistance to lateral flow diversion either side of the turbines. Consequently, it is much easier for flow to divert around turbines towards the ends of an array than those closer to the centre [83], [85]. Differences in turbine loading across a fence may lead to different rates of blade degradation and fatigue lifetime, and therefore there is interest in developing strategies such as cross-fence differential turbine operation to mitigate these effects [83], [85].

As in the wind industry, turbine control is an important method of economically matching the potential revenue available at a site to the cost of a turbine. Power capping is employed at a level where it is considered to be economical to design and operate a turbine based on the local flow conditions. The close coupling between turbine resistance and the available tidal resource means that this is a more closely coupled than it has been for the wind industry to date. An approach for mitigating the impact that tidal stream turbines have on the tidal environment is to implement control strategies such as power capping in which turbine thrust is reduced. This is typically achieved through pitch-tofeather control of the turbines above rated flow speed. The reduction in thrust at the highest channel flow speeds may help sustain flow through the channel, and thereby maximise the exploitation of the tidal resource as compared to operation that does not reduce thrust [86], [87]. 


\section{National and commercial support for tidal stream energy}

\subsection{National support}

Tidal stream energy has enjoyed some notable successes in the UK in recent years, and the UK is host to a number of leading tidal energy companies. This is supported by significant research and government support of the sector. Research leadership in the area is provided by the Supergen ORE hub, successor to Supergen UKCMER. In addition to approximately $f 300 \mathrm{~m}$ research and development funding from UK sources, UK organisations have also benefited from over $€ 60 \mathrm{~m}$ research and development funding from European funding mechanisms, including FP7 and H2020 [88].

Support for tidal stream energy is less developed in South America at present, likely due to the nascent stage of technological development. As discussed in Section 2, there are a few sites around the continent with high flow speeds and significant tidal stream energy potential, and characterisation studies have been started into better understanding the available resource e.g. [26], [27], [36]. However, most South American sites are less energetic than currently being investigated with existing tidal stream technologies and further developments are required to access lower flow speeds.

The Marine Energy Research and Innovation Center (MERIC) in Chile supports a wide range of research and development projects for marine (both wave and tidal) energy [89]. Chile's "Energy Policy for 2050" outlines the increase of renewable energy technologies within the energy matrix as one of the main goals of the country, including tidal energy [90]. Public support for renewable energy development in Chile is quite high; for example, a survey of acceptance of renewable energy development locally in communities found that $90 \%$ of respondents would not object to a tidal power plant development [90]. Development of tidal and hydrokinetic energy has been explored in Brazil since the 1980s in a number of different pilot projects and studies [35], and is being monitored at a national level in Brazil, although the Brazilian Development Bank reported no projects being approved between 2003 and 2015 [91].

South America currently lacks open sea test facilities for tidal stream energy [11], although three facilities are available for experiments with small turbines [92]. Two are located in Brazil, more specifically at Ïnstituto de Pesquisas Tecnológicas - IPT, located at University of São Paulo and LabOceano at COPPE (Federal University of Rio de Janeiro) and one in Chile, at "Universidad Austral de Chile".

\subsection{Companies}

The interest of Original Equipment Manufacturers (OEMs) in tidal stream energy has had an important role in the development of the sector. Over the last decade, major OEMs around the world have entered the market such as Alstom, Andritz, DCNS, Hyundai Heavy Industries ( $\mathrm{HHI}$ ), Kawasaki Heavy Industries (KHI), Siemens, Voith Hydro and General Electric (GE). However, in order to decrease the risk of such novel technologies they have also sought co-funding with governments [93]. Due to the available support and funding mechanisms, most OEMs are located in Europe.

These tidal stream technology developers have different focus regarding the turbine design, which can be horizontal axis flow, cross-flow, vertical axis flow, fixed on the seabed or floating, etc. Nevertheless, it is possible to see a trend across developers. $76 \%$ of the technologies are for horizontal axis flow, $56 \%$ are connected with the seabed while $36 \%$ are floating systems and $68 \%$ are focused on single turbine per structure systems, as compared to $32 \%$ that seek to develop multiple rotor structures [93]. 
In 2018 the UK was home to 22 active tidal stream technology developers, including some gridconnected demonstrators and the world's first tidal stream turbine array [94]. A range of technological solutions have been proposed, including floating and seabed-mounted support systems, as well as large and small diameter rotors.

Companies that have adopted large diameter rotors include SIMEC Atlantis and Orbital Marine Power (Figure 5). SIMEC Atlantis' MeyGen $1 \mathrm{~A}$ project in the Pentland Firth consists four seabedmounted $18 \mathrm{~m}$ diameter turbines with a total capacity of $6 \mathrm{MW}$ as the first stage towards the development of the full $86 \mathrm{MW}$ project that has been consented. Future extensions to the project would to install up to $398 \mathrm{MW}$ at the site [95]. Phase $1 \mathrm{~A}$ of the project was commissioned in April 2018 and delivered over $10 \mathrm{GWh}$ to the grid [11]. Orbital Marine Power have been testing their SR2000 $2 \mathrm{MW}$, two-rotor device at the EMEC site, demonstrating the ability to generate over $3 \mathrm{GWh}$ in a year. The SR2000 consists of two $16 \mathrm{~m}$ diameter rotors supported from a floating platform [96].

An alternative approach being pursued is to use smaller diameter rotors in order to reduce turbine loading. Nova Innovation have developed a 9m diameter $100 \mathrm{~kW}$ device, which has been demonstrated and grid-connected at Bluemull Sound in the Shetland Islands since 2016 [97]. The device is mounted on a gravity foundation on the seabed. Additional turbines have been added over time, and the $€ 20.2 \mathrm{~m} \mathrm{H} 2020$ EnFAIT project will further extend the existing array to 6 turbines [88]. Sustainable Marine Energy have also adopted the approach of using multiple small rotors although utilise a floating support structure for ease of access for maintenance. The Plat-I and Plat-O systems use four $4 \mathrm{~m}$ diameter Schottel turbines on a floating platform, and the Plat- $\mathrm{O}$ system has been demonstrated at EMEC [98].

\subsection{Cost of energy}

Despite the recent successful deployments of tidal devices in the UK, further reductions in LCOE are required for commercial success. Revenue support for renewable energy technologies in the UK is offered through the Contracts for Difference (CfD) programme. Draft strike prices of $£ 225 / \mathrm{MWh}$ in $2023 / 24$ and $f 217 / M W h$ in $2024 / 25$ were quoted in 2017, although without specific allocation of funding to tidal stream energy, it is unlikely to be competitive in an auction in competition with offshore wind, which is forecast for strike prices of $£ 56 / \mathrm{MWh}$ and $f 53 / \mathrm{MWh}$ in 2023/24 and 2024/25 respectively [88]. Significant cost reductions are expected to be achieved through further technical innovations, financing cost reductions as the technologies mature, and economies of scale, with LCOE estimated to reduce to $f 90 / \mathrm{MWh}$ once $1 \mathrm{GW}$ has been deployed [94].

\section{Challenges and Opportunities}

Tidal stream energy presents a significant and worthwhile opportunity as a predictable and renewable source of energy in countries with significant tidal resources. The UK and Brazil in particular benefit from established offshore energy sectors, primarily focussed on oil and gas, providing a base of industrial and academic experience for developing new offshore technologies.

However, significant reduction in LCOE need to be achieved before tidal stream energy will be competitive with alternative technologies such as wind and solar photovoltaics. The fluid dynamic similarities between wind and tidal stream energy has allowed significant transfer of knowledge from the former industry to the later, although there are important differences between the two applications, in particular the effects of blockage. Whilst the harsh marine environment, including the 
effects of waves, shear profile and high levels of ambient turbulence present challenges in the design and operation of tidal turbines, blockage also presents an opportunity to substantially boost tidal turbine performance relative to that for wind turbines. Indeed, recent experiments on turbines designed for operating in a blocked environment have shown that a substantial uplift in performance of approximately $20 \%$ can be achieved [72]. Of course, advanced materials, coatings and control strategies will be required to fully benefit from tidal stream technology at a commercial scale.

A significant challenge in the development of renewable energy technologies is that they typically involve large upfront investments, with payback occurring over extended periods. Investor confidence in the sector will therefore benefit from the long-term demonstration of performance and maintainability of tidal turbines, as is currently being demonstrated by a number of UK tidal energy companies at testing centres and the first commercial arrays. This will also demonstrate to policy makers the potential of tidal stream energy to contribute to national electricity supplies and develop the case for supporting nascent technologies. The existing offshore energy infrastructure in countries such as Brazil and the UK provide opportunities for integrating tidal energy into the existing energy network.

The development of the supporting science and engineering for tidal stream energy requires a broad range analytic, numerical and experimental techniques. The multi-scale modelling approach that links the hydrodynamics of individual turbines to farm-scale dynamics and the interaction with the tidal resource is now being applied to wind energy as emergent farm-scale flow physics is becoming increasingly important as offshore wind farms become larger [99]-[102]. Furthermore, the impact of wind farms on local weather systems is being observed over scales of tens of kilometres [103], [104], and represents an opportunity to consider energy extraction from wind and tidal flows as two applications of a fundamentally similar problem.

This article has outlined how energy may be harnessed from the tides, and demonstrated that there is commonality in the technological, environmental and commercial challenges faced by countries seeking to harness tidal stream energy. Collaborative international research and development is required to meet these challenges. Advances are required to reduce costs through improved design, maintenance and operation of tidal turbines, as well as improved confidence in the industry to support future investment. The international challenge is to develop the sector by building on existing strengths and developing new research and commercial opportunities in a way that provide sustainable and environmentally sensitive power that can be integrated into future energy networks.

\section{Acknowledgements}

The authors gratefully acknowledge support from the Oxford-FAPESP (Fundação de Amparo à Pesquisa do Estado de São Paulo) SPRINT project "UK-Brazil collaboration for the development of renewable energy: gas, air and water" (2017/50159-7) and FAPESP Shell Research Centre for Gas Innovation - RCGI (2014/50279-4). DTT acknowledges support from BEPE Iniciação Científica project 2018/23651-0.

\section{References}

[1] 'Transforming Our World: The 2030 Agenda for Sustainable Development', United Nations, UN General Assembly Resolution A/RES/70/1, Oct. 2015. 
[2] IPCC, 'Summary for Policymakers', in Global warming of $1.5^{\circ} \mathrm{C}$, Geneva, Switzerland: World Meteorological Organization, 2018, p. 32.

[3] CCC, 'Net zero: The UK's contribution to stopping global warming', Committee on Climate Change, London, UK, 2019.

[4] J. Shaw, Climate Change Response (Zero Carbon) Amendment Bill. 2019.

[5] I. Staffell, 'Measuring the progress and impacts of decarbonising British electricity', Energy Policy, vol. 102, pp. 463-475, 2017.

[6] BEIS, 'UK Energy in brief 2018', Department for Business, Energy \& Industrial Strategy, London, Government Report, 2018.

[7] MME, 'Resenha Energética Brasileira 2018', Ministério de Minas e Energia, Brasilia, Government Report, 2018.

[8] IEA, World Energy Outlook 2015. Paris, France: International Energy Agency, 2015.

[9] IEA, Renewables 2018. Paris, France: International Energy Agency, 2018.

[10] S. Rodrigues, C. Restrepo, E. Kontos, R. Teixeira Pinto, and P. Bauer, 'Trends in offshore wind projects', Renew. Sustain. Energy Rev., vol. 49, pp. 1114-1135, 2015.

[11] IEA, Offshore energy outlook. Paris, France: International Energy Agency, 2018.

[12] H. Lund and B. V. Mathiesen, 'Energy system analysis of $100 \%$ renewable energy systems-The case of Denmark in years 2030 and 2050', Energy, vol. 34, no. 5, pp. 524-531, 2009.

[13] M. J. Grubb, 'The integration of renewable electricity sources', Energy Policy, vol. 19, no. 7, pp. 670-688, 1991.

[14] J. Callaghan and R. Boud, Future Marine Energy. London: Carbon Trust, 2006.

[15] R. Pelc and R. M. Fujita, 'Renewable energy from the ocean', Mar. Policy, vol. 26, pp. 471-479, 2002.

[16] A. G. L. Borthwick, 'Marine Renewable Energy Seascape', Engineering, vol. 2, no. 1, pp. 69-78, 2016.

[17] P. S. Laplace, 'Théorie des attractions des sphéroïdes et de la figure de la terre', Mém. Académie Sci. Paris, pp. 341-419, 1782.

[18] A. Defant, Physical Oceanography, vol. 11. New York: Pergamon Press, 1961.

[19] R. A. Plumb and J. Marshall, Atmosphere, Ocean and Climate Dynamics. New York: Academic Press, 2007.

[20] R. Vennell, 'Realizing the potential of tidal currents and the efficiency of turbine farms in a channel', Renew. Energy, vol. 47, pp. 95-102, 2012.

[21] ABPmer, 'Atlas of UK Marine Renewable Energy Resources', ABP Marine Environmental Research, Southampton, UK, Technical Report R.1432, 2008.

[22] Black \& Veatch, 'UK Tidal Current Resource and Economics', Carbon Trust, London, 2010.

[23] B. Wilson, S. Benjamins, and J. Elliott, 'Using drifting passive echolocation loggers to study harbour porpoises in tidal-stream habitats', Endanger. Species Res., vol. 22, no. 2, pp. 125-143, 2013.

[24] L. Lieber, W. A. M. Nimmo-Smith, J. J. Waggitt, and L. Kregting, 'Fine-scale hydrodynamic metrics underlying predator occupancy patterns in tidal stream environments', Ecol. Indic., vol. 94, pp. 397-408, 2018.

[25] M. K. Pine, P. Schmitt, R. M. Culloch, L. Lieber, and L. T. Kregting, 'Providing ecological context to anthropogenic subsea noise: Assessing listening space reductions of marine mammals from tidal energy devices', Renew. Sustain. Energy Rev., vol. 103, pp. 49-57, 2019.

[26] E. González-Gorbeña, P. C. C. Rosman, and R. Y. Qassim, 'Assessment of the tidal current energy resource in São Marcos Bay, Brazil', J. Ocean Eng. Mar. Energy, vol. 1, no. 4, pp. 421-433, 2015.

[27] M. Guerra, R. Cienfuegos, J. Thomson, and L. Suarez, 'Tidal energy resource characterization in Chacao Channel, Chile', Int. J. Mar. Energy, vol. 20, pp. 1-16, Dec. 2017.

[28] M. Cáceres, A. Velle-Levinson, and L. Atkinson, 'Observations of cross-channel structure of flow in an energetic tidal channel', J. Geophys. Res., vol. 108, no. C4, p. 3114, 2003. 
[29] C. M. Aiken, 'Barotropic tides of the Chilean Inland Sea and their sensitivity to basin geometry', J. Geophys. Res., vol. 113, p. C08024, 2008.

[30] Garrad Hassan, 'Preliminary site selection - Chilean marine energy resources', Inter-American Development Bank, Brasília, Brazil, Technical Report 100513/BR/02, 2009.

[31] R. Alonso, M. Jackson, P. Santoro, M. Fossati, S. Solari, and L. Teixeira, 'Wave and tidal energy resource assessment in Uruguayan shelf seas', Renew. Energy, vol. 114, pp. 18-31, Dec. 2017.

[32] V. Villalón, D. Watts, and R. Cienfuegos, 'Assessment of the power potential extraction in the Chilean Chacao channel', Renew. Energy, vol. 131, pp. 585-596, Feb. 2019.

[33] R. Hucke-Gaete, L. P. Osman, C. A. Moreno, K. P. Findlay, and D. K. Ljungblad, 'Discovery of a blue whale feeding and nursing ground in southern Chile', Proc. R. Soc. Lond. B Biol. Sci., vol. 271, pp. S170-S173, 2004.

[34] M. Marta-Almeida, M. Cirano, C. Guedes Soares, and G. C. Lessa, 'A numerical tidal stream energy assessment study for Baía de Todos os Santos, Brazil', Renew. Energy, vol. 107, pp. 271287, Jul. 2017.

[35] R. H. van Els and A. C. P. B. Junior, 'The Brazilian experience with hydrokinetic turbines', Energy Procedia, vol. 75, pp. 259-264, Aug. 2015.

[36] E. de P. Kirinus, P. H. Oleinik, J. Costi, and W. C. Marques, 'Long-term simulations for ocean energy off the Brazilian coast', Energy, vol. 163, pp. 364-382, Nov. 2018.

[37] C. Garrett and P. Cummins, 'The power potential of tidal currents in channels', Proc. R. Soc. Math. Phys. Eng. Sci., vol. 461, no. 2060, pp. 2563-2572, 2005.

[38] S. Draper, G. T. Houlsby, M. L. G. Oldfield, and A. G. L. Borthwick, 'Modelling tidal energy extraction in a depth-averaged coastal domain', IET Renew. Power Gener., vol. 4, no. 6, pp. 545554, 2010.

[39] R. Vennell, 'Tuning turbines in a tidal channel', J. Fluid Mech., vol. 663, pp. 253-267, 2010.

[40] P. F. Cummins, R. H. Karsten, and B. K. Arbic, 'The semi-diurnal tide in Hudson strait as a resonant channel oscillation', Atmosphere-Ocean, vol. 48, no. 3, pp. 163-176, 2010.

[41] P. C. Roos and H. M. Schuttelaars, 'Influence of topography on tide propagation and amplification in semi-enclosed basins', Ocean Dyn., vol. 61, no. 1, pp. 21-38, Jan. 2011.

[42] C. R. Vogel, R. H. J. Willden, and G. T. Houlsby, 'Power available from a depth-averaged simulation of a tidal turbine array', Renew. Energy, vol. 114, pp. 513-524, 2017.

[43] T. A. A. Adcock, S. Draper, G. T. Houlsby, A. G. L. Borthwick, and S. Serhadlıoğlu, 'Tidal stream power in the Pentland Firth - long-term variability, multiple constituents and capacity factor', Proc. Inst. Mech. Eng. Part J. Power Energy, vol. 228, no. 8, pp. 854-861, 2014.

[44] M. J. Kreitmair, S. Draper, A. G. L. Borthwick, and T. S. van den Bremer, 'The effect of uncertain bottom friction on estimates of tidal current power', R. Soc. Open Sci., vol. 6, no. 1, p. 180941, 2019.

[45] S. Serhadlıoğlu, T. A. A. Adcock, G. T. Houlsby, S. Draper, and A. G. L. Borthwick, 'Tidal stream energy resource assessment of the Anglesey Skerries', Int. J. Mar. Energy, vol. 3-4, pp. 98-111, 2013.

[46] S. C. Kramer and M. D. Piggott, 'A correction to the enhanced bottom drag parameterisation of tidal turbines', Renew. Energy, vol. 92, pp. 385-396, 2016.

[47] S. Muchala and R. H. J. Willden, 'Impact of tidal turbine support structures on realizable turbine farm power', Renew. Energy, vol. 114, pp. 588-599, 2017.

[48] C. Garrett and P. Cummins, 'The efficiency of a turbine in a tidal channel', J. Fluid Mech., vol. 588, pp. 243-251, 2007.

[49] J. I. Whelan, J. M. R. Graham, and J. Peiró, 'A free-surface and blockage correction for tidal turbines', J. Fluid Mech., vol. 624, pp. 281-291, 2009.

[50] G. T. Houlsby and C. R. Vogel, 'The power available to tidal turbines in an open channel flow', Proc. Inst. Civ. Eng. - Energy, vol. 170, no. 1, pp. 12-21, 2017.

[51] C. S. K. Belloni, R. H. J. Willden, and G. T. Houlsby, 'A Numerical Analysis of Bidirectional Ducted Tidal Turbines in Yawed Flow', Mar. Technol. Soc. J., vol. 47, no. 4, pp. 23-35, 2013. 
[52] T. Nishino and R. H. J. Willden, 'The efficiency of an array of tidal turbines partially blocking a wide channel', J. Fluid Mech., vol. 708, pp. 596-606, 2012.

[53] C. R. Vogel, G. T. Houlsby, and R. H. J. Willden, 'Effect of free surface deformation on the extractable power of a finite width turbine array', Renew. Energy, vol. 88, pp. 317-324, 2016.

[54] A. Wimshurst, C. R. Vogel, and R. H. J. Willden, 'Cavitation limits on tidal turbine performance', Ocean Eng., vol. 152, pp. 223-233, 2018.

[55] J. Schluntz and R. H. J. Willden, 'The effect of blockage on tidal turbine rotor design and performance', Renew. Energy, vol. 81, pp. 432-441, 2015.

[56] C. F. Fleming, S. C. Mclntosh, and R. H. J. Willden, 'Design and analysis of a bi-directional ducted tidal turbine', in Proceedings of the European Wave and Tidal Energy Conference (EWTEC), Southampton, UK, 2011.

[57] T. Burton, N. Jenkins, D. Sharpe, and E. A. Bossanyi, Wind Energy Handbook, 2nd ed. Chichester, UK: Wiley, 2011.

[58] S. A. Ning, 'A simple solution method for the blade element momentum equations with guaranteed convergence', Wind Energy, vol. 17, pp. 1327-1345, 2014.

[59]Z. Sun, J. Chen, W. Z. Shen, and W. J. Zhu, 'Improved blade element momentum theory for wind turbine aerodynamic computations', Renew. Energy, vol. 96, pp. 824-831, 2016.

[60] H. Glauert, 'Airplane propellers', in Aerodynamic theory, Berlin Heidelberg: Springer-Verlag, 1935, pp. 167-269.

[61] M. L. Buhl Jr., 'New Empirical Relationship between Thrust Coefficient and Induction Factor for the Turbulent Windmill State', NREL/TP-500-36834, 15016819, Aug. 2005.

[62] W. Z. Shen, R. F. Mikkelsen, J. N. Sørensen, and C. Bak, 'Tip loss corrections for wind turbine computations', Wind Energy, vol. 8, pp. 457-475, 2005.

[63] C. R. Vogel, R. H. J. Willden, and G. T. Houlsby, 'Blade element momentum theory for a tidal turbine', Ocean Eng., vol. 169, pp. 215-226, 2018.

[64] S. C. McIntosh, C. F. Fleming, and R. H. J. Willden, 'Embedded RANS-BEM Tidal Turbine Design', in 9th European Wave and Tidal Energy Conference (EWTEC), Southampton, UK, 2011, p. 10.

[65] P.-E. Réthoré, P. van der Laan, N. Troldborg, F. Zahle, and N. N. Sørensen, 'Verification and validation of an actuator disc model', Wind Energy, vol. 17, no. 6, pp. 919-937, 2014.

[66] J. Hennen and S. Kenjereš, 'Contribution to improved eddy-viscosity modeling of the wind turbine - to - wake interactions', Int. J. Heat Fluid Flow, vol. 68, pp. 319-336, 2017.

[67] F. Pierella, P.-Å. Krogstad, and L. Sætran, 'Blind test 2 calculations for two in-line model wind turbines where the downstream turbine operates at various rotational speeds', Renew. Energy, vol. 70, pp. 62-77, 2014.

[68] N. Troldborg, F. Zahle, P.-E. Réthoré, and N. N. Sørensen, 'Comparison of wind turbine wake properties in non-sheared inflow predicted by different computational fluid dynamics rotor models', Wind Energy, vol. 18, no. 7, pp. 1239-1250, 2015.

[69] W. A. Timmer and R. P. O. J. M. van Rooij, 'Summary of Delft wind turbine airfoils', Trans. Am. Soc. Mech. Eng., vol. 125, pp. 488-496, 2003.

[70] P. Fuglsang and C. Bak, 'Development of the Ris $\varnothing$ wind turbine airfoils', Wind Energy, vol. 7, pp. 145-162, 2004.

[71] B. Cao, R. H. J. Willden, and C. R. Vogel, 'Effects of blockage and freestream turbulence intensity on tidal rotor design and performance', in Proceedings of the 3rd International Conference on Renewable Energies (RENEW), Lisbon, Portugal, 2018, pp. 127-136.

[72] J. McNaughton, B. Cao, C. R. Vogel, and R. H. J. Willden, 'Model scale testing of multi-rotor arrays designed to exploit constructive interference effects', in Proceedings of the 13th European Wave and Tidal Energy Conference (EWTEC), Naples, Italy, 2019.

[73] L. Zhang, S. Wang, Q. Sheng, F. Jing, and Y. Ma, 'The effects of surge motion of the floating platform on hydrodynamics performance of horizontal-axis tidal current turbine', Renew. Energy, vol. 74, pp. 796-802, 2015. 
[74] Q. Sheng, F. Jing, L. Zhang, N. Zhou, S. Wang, and Z. Zhang, 'Study of the hydrodynamic derivatives of vertical-axis tidal current turbines in surge motion', Renew. Energy, vol. 96, pp. 366-376, 2016.

[75] M. H. bin Osman, R. H. J. Willden, and C. R. Vogel, 'The effects of surge motion on floating horizontal axis tidal turbines', in Proceedings of the 13th European Wave and Tidal Energy Conference (EWTEC), Naples, Italy, 2019, p. 10.

[76] D. Micallef and T. Sant, 'Loading effects on floating offshore horizontal axis wind turbines in surge motion', Renew. Energy, vol. 83, pp. 737-748, 2015.

[77] Y. Liu, S. Yoshida, H. Yamamoto, A. Toyofuku, G. He, and S. Yang, 'Response Characteristics of the DeepCwind Floating Wind Turbine Moored by a Single-Point Mooring System', Appl. Sci., vol. 8, no. 11, p. 2306, 2018.

[78] Y. Liu et al., 'A reliable open-source package for performance evaluation of floating renewable energy systems in coastal and offshore regions', Energy Convers. Manag., vol. 174, pp. 516-536, 2018.

[79] V. Gupta and A. M. Young, 'A one-dimensional model for tidal array design based on three-scale dynamics', J. Fluid Mech., vol. 825, pp. 651-676, 2017.

[80] L. Chen, P. A. J. Bonar, C. R. Vogel, and T. A. A. Adcock, 'A note on the tuning of tidal turbines in channels', J. Ocean Eng. Mar. Energy, vol. 5, no. 1, pp. 85-98, Feb. 2019.

[81] S. C. Cooke, R. H. J. Willden, B. W. Byrne, T. Stallard, and A. Olczak, 'Experimental Investigation of Thrust and Power on a Partial Fence Array of Tidal Turbines', in Proceedings of the 11th European Wave and Tidal Energy Conference, Nantes, France, 2015, pp. 09D2-5.

[82] F. Heathcote, C. R. Vogel, and R. h. J. Willden, 'Design and operation of a $1 \mathrm{MW}$ four turbine tidal fence', in Progress in Renewable Energies Offshore, Lisbon, Portugal, 2016, pp. 545-552.

[83] C. R. Vogel and R. H. J. Willden, 'Multi-rotor tidal stream turbine fence performance and operation', Int. J. Mar. Energy, vol. 19, pp. 198-206, 2017.

[84] C. R. Vogel and R. H. J. Willden, 'Designing Multi-Rotor Tidal Turbine Fences', Int. Mar. Energy J., vol. 1, no. 1, pp. 61-70, 2018.

[85] C. R. Vogel and R. H. J. Willden, 'Improving Tidal Turbine Performance Through Multi-Rotor Fence Configurations', J. Mar. Sci. Appl., vol. 18, no. 1, pp. 17-25, 2019.

[86] R. Vennell and T. A. A. Adcock, 'Energy storage inherent in large tidal turbine farms', Proc. R. Soc. Math. Phys. Eng. Sci., vol. 470, no. 2166, pp. 20130580-20130580, 2014.

[87] C. R. Vogel, R. H. J. Willden, and G. T. Houlsby, 'Tidal stream turbine power capping in a headdriven tidal channel', Renew. Energy, vol. 136, pp. 491-499, 2019.

[88] A. Brito e Melo and H. Jeffrey, An overview of ocean energy activities in 2018. Lisbon, Portugal: International Energy Agency, 2018.

[89] MERIC, 'MERIC | Marine energy research \& innovation center', 16-Jul-2019. [Online]. Available: https://www.meric.cl/en/home/.

[90] Ministerio de Energía, 'Energy 2050 Chile's Energy Policy', Ministerio de Energía de Chile, Santiago, Chile, Government Report, 2015.

[91] BNDES, 'Consulta a operações do BNDES', 16-Jul-2019. [Online]. Available: https://www.bndes.gov.br/wps/portal/site/home/transparencia/.

[92] ITTC, 'International Towing Tank Conference | Catalogue of Facilities', 18-Jul-2019. [Online]. Available: https://ittc.info/facilities/.

[93] IRENA, 'Ocean Energy: Technology readiness, patents, deployment status and outlook', International Renewable Energy Agency, Abu Dhabi, United Arab Emirates, Technical Report, 2014.

[94] G. Smart and M. Noonan, 'Tidal stream and wave energy cost reduction and industrial benefit', Offshore Renewable Energy Catapult, Glasgow, UK, Technical Report, 2018.

[95] SIMEC Atlantis, 'SIMEC Atlantis', SIMEC Atlantis Energy / A global sustainable energy company, 08-Jul-2019. [Online]. Available: https://simecatlantis.com/. 
[96] Orbital Marine Power, 'Orbital Marine Power - the world leader in the development of floating tidal stream and run-of-river turbines', 08-Jul-2019. [Online]. Available: https://orbitalmarine.com/index.php.

[97] Nova Innovation, 'Nova Innovation | Tidal Energy and Turbine Developers', 08-Jul-2019. [Online]. Available: https://www.novainnovation.com/.

[98] Sustainable Marine Energy, 'Tidal Energy | Marine Energy | Technology', 08-Jul-2019. [Online]. Available: https://sustainablemarine.com/.

[99] R. J. Barthelmie et al., 'Modelling and measuring flow and wind turbine wakes in large wind farms offshore', Wind Energy, vol. 12, pp. 431-444, 2009.

[100] M. Gaumond et al., 'Benchmarking of wind turbine wake models in large offshore wind farms', in Proceedings of The Science of Making Torque from Wind, Oldenburg, Germany, 2012.

[101] E. Machefaux, G. C. Larsen, and J. P. Murcia Leon, 'Engineering models for merging wakes in wind farm optimization applications', J. Phys. Conf. Ser., vol. 625, p. 012037, Jun. 2015.

[102] K. Gunn et al., 'Limitations to the validity of single wake superposition in wind farm yield assessment', J. Phys. Conf. Ser., vol. 749, p. 012003, 2016.

[103] A. C. Fitch et al., 'Local and Mesoscale Impacts of Wind Farms as Parameterized in a Mesoscale NWP Model', Mon. Weather Rev., vol. 140, no. 9, pp. 3017-3038, 2012.

[104] A. C. Fitch, J. K. Lundquist, and J. B. Olson, 'Mesoscale Influences of Wind Farms throughout a Diurnal Cycle', Mon. Weather Rev., vol. 141, no. 7, pp. 2173-2198, 2013.
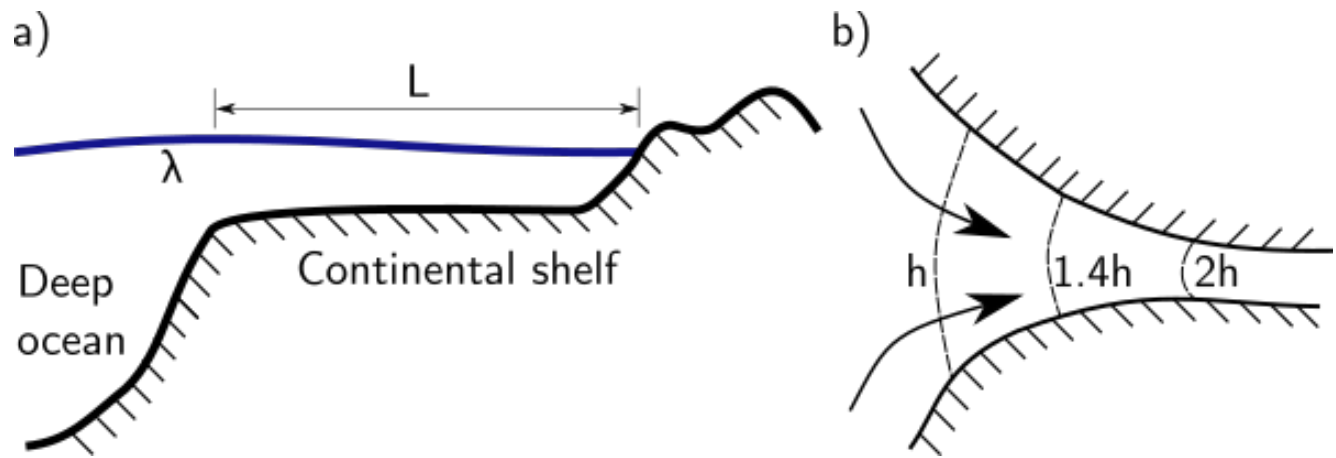

Figure 1: Schematic of (a) resonance between deep oceans and the continental shelf and (b) the focussing of tidal amplitude due to an estuary or channel. 


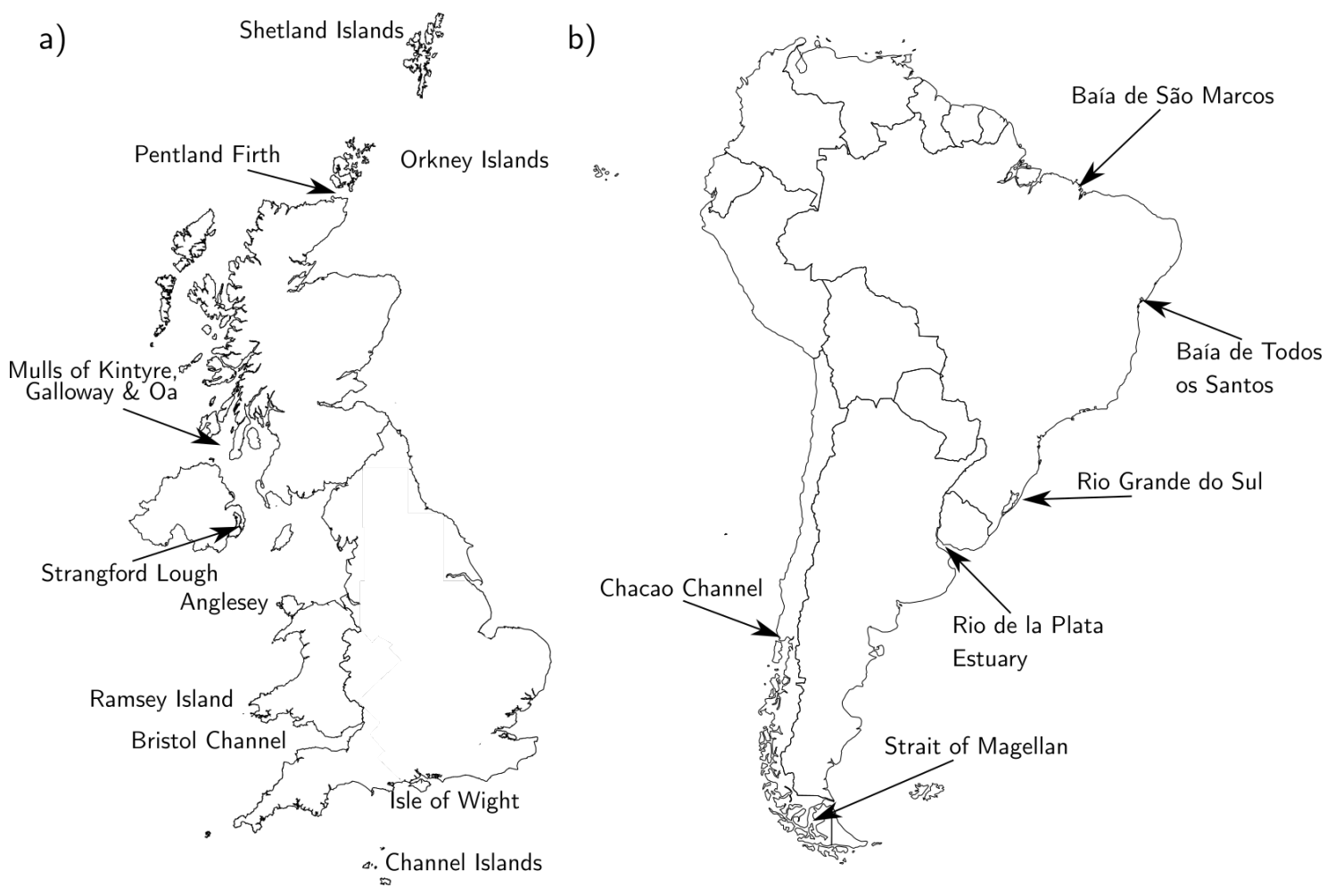

Figure 2: Regions where potential for tidal stream energy development has been identified in (a) the United Kingdom and (b) South America.

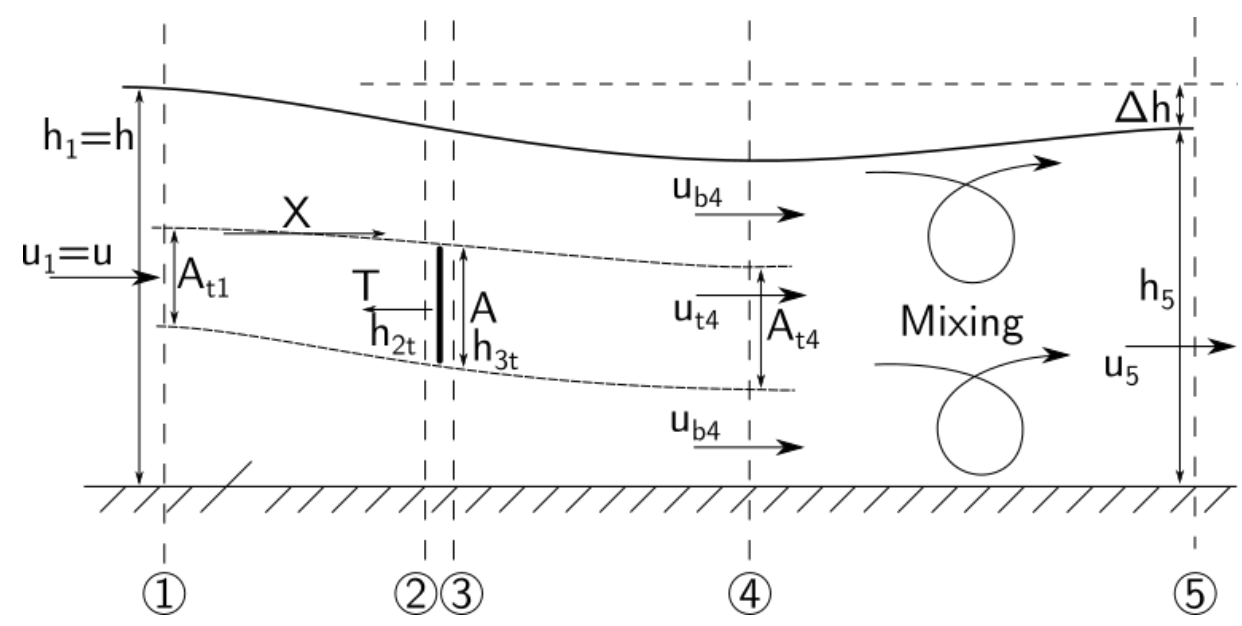

Figure 3: Schematic of energy extraction from an open channel flow by an idealised turbine. Adapted from [50]. 


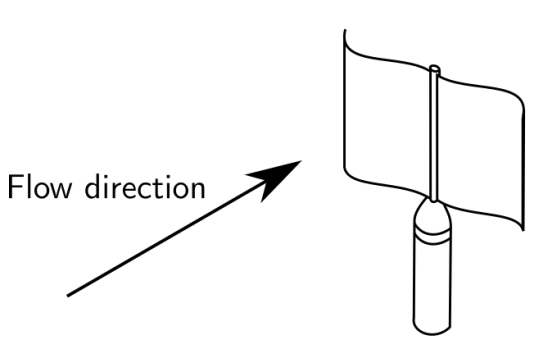

a)

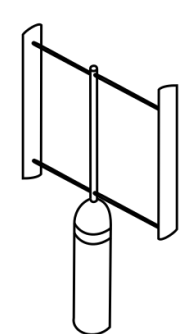

b)

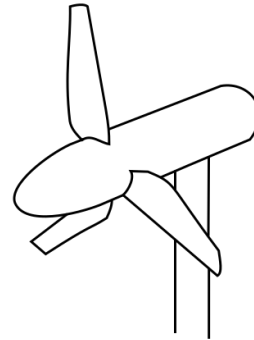

c)

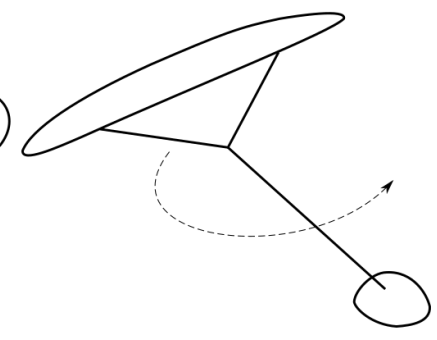

d)

Figure 4: Examples of different classes of devices proposed for tidal stream energy extraction. Broadly, devices can be classified into drag devices, such as Savonius turbines (a), and lifting devices, such as (b) cross-flow turbines, (c) axial flow turbines and (d) lifting hydrofoils.

a)

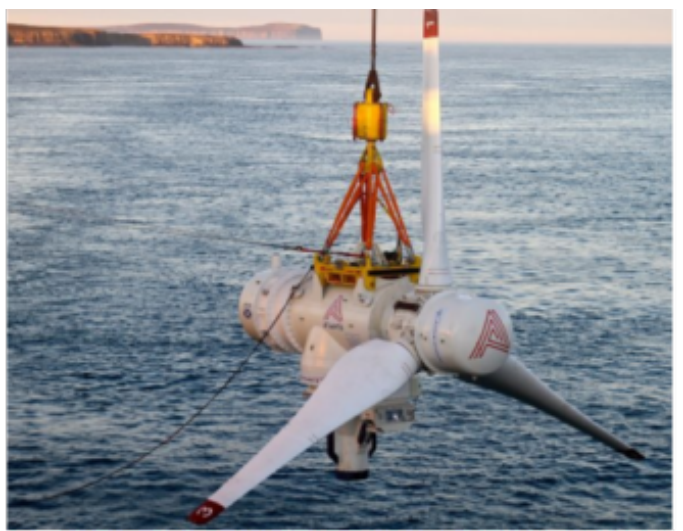

c)

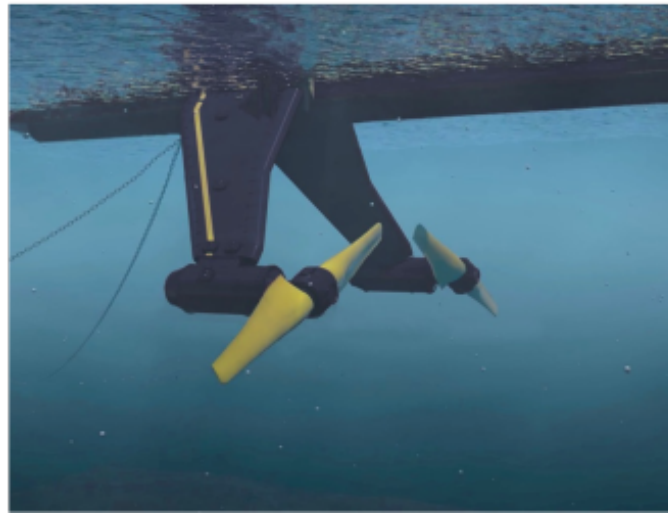

b)

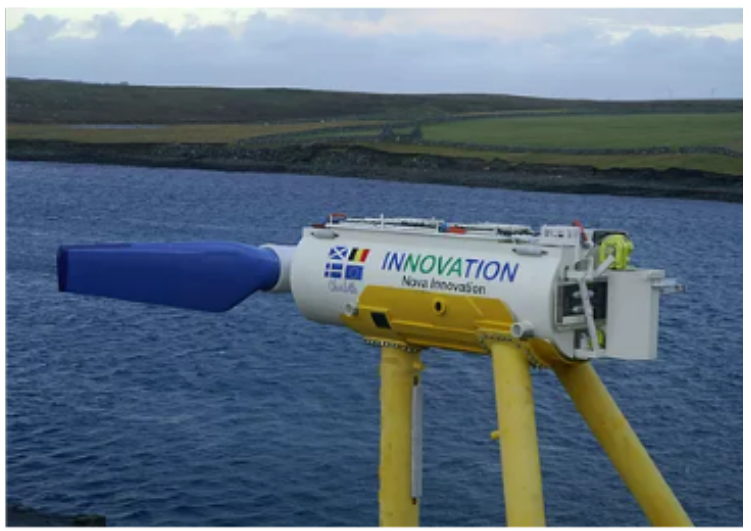

d)

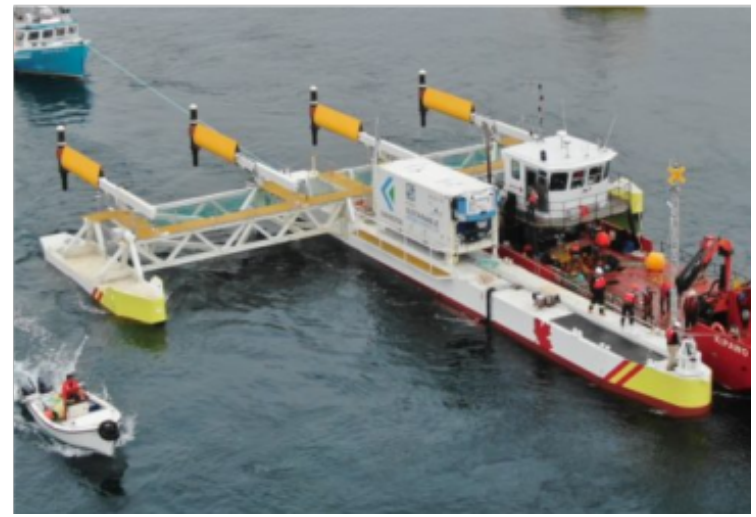

Figure 5: Commercial and demonstration tidal energy devices. (a) SIMEC Atlantis AR1500 turbine [95], (b) Nova Innovation Nova M100 turbine [97], (c) Orbital Marine Power Orbital O2 2MW turbine [96], d) Sustainable Marine Energy PLAT-I [98]. 